\title{
Correction to: Characterization of functional traits with focus on udder health in heifers with divergent paternally inherited haplotypes on BTA18
}

A. Heimes ${ }^{1}$, J. Brodhagen ${ }^{1}$, R. Weikard ${ }^{1}$, H. M. Hammon ${ }^{2}$, M. M. Meyerholz ${ }^{3}$, W. Petzl ${ }^{3}$, H. Zerbe ${ }^{3}$, S. Engelmann ${ }^{4,5}$, M. Schmicke ${ }^{6}$, M. Hoedemaker $^{6}$, H.-J. Schuberth ${ }^{7}$ and C. Kühn ${ }^{1,8^{*}}$

\section{Correction to: BMC Vet Res (2019) 15:241 \\ https://doi.org/10.1186/s12917-019-1988-4}

The original article [1] contained an error whereby the captions to Figs. 2 and 3 were mistakenly inverted; this has now been corrected.

Furthermore, this error was mistakenly introduced by the production team handling the manuscript and thus, was not the fault of the authors.

\begin{abstract}
Author details
'Leibniz Institute for Farm Animal Biology (FBN), Institute of Genome Biology, Wilhelm-Stahl-Allee 2, 18196 Dummerstorf, Germany. ${ }^{2}$ Leibniz Institute for Farm Animal Biology (FBN), Institute of Nutritional Physiology, Wilhelm-Stahl-Allee 2, 18196 Dummerstorf, Germany. ${ }^{3}$ Clinic for Ruminants with Ambulatory and Herd Health Services, Centre for Clinical Veterinary Medicine, Ludwig-Maximilians-University Munich, Sonnenstr. 16, 85764 Oberschleißheim, Germany. ${ }^{4}$ Institute for Microbiology, Technical University Braunschweig, Postfach 3329, 38023 Braunschweig, Germany. ${ }^{5}$ Microbial Proteomics, Helmholtz Centre for Infection Research, Inhoffenstraße 7, 38124 Braunschweig, Germany. ${ }^{6}$ Clinic for Cattle, University of Veterinary Medicine Hanover, Bischofsholer Damm 15, 30173 Hanover, Germany. ${ }^{7}$ Immunology Unit, University of Veterinary Medicine Hanover, Bünteweg 2, Geb. 261, 30559 Hanover, Germany. ${ }^{8}$ Agricultural and Environmental Faculty, University Rostock, Justus-von-Liebig-Weg 6, 18059 Rostock, Germany.
\end{abstract}

Published online: 08 August 2019

\section{Reference}

1. Heimes A, Brodhagen J, Weikard R, Hammon HM, Meyerholz MM, Petzl W, et al.

Characterization of functional traits with focus on udder health in heifers with divergent paternally inherited haplotypes on BTA18. BMC Vet Res. 2019;15:241. https://doi.org/10.1186/s12917-019-1988-4.

\footnotetext{
* Correspondence: kuehn@fbn-dummerstorf.de

'Leibniz Institute for Farm Animal Biology (FBN), Institute of Genome Biology,

Wilhelm-Stahl-Allee 2, 18196 Dummerstorf, Germany

${ }^{8}$ Agricultural and Environmental Faculty, University Rostock,

Justus-von-Liebig-Weg 6, 18059 Rostock, Germany

Full list of author information is available at the end of the article
}

(c) The Author(s). 2019 Open Access This article is distributed under the terms of the Creative Commons Attribution 4.0 International License (http://creativecommons.org/licenses/by/4.0/), which permits unrestricted use, distribution, and reproduction in any medium, provided you give appropriate credit to the original author(s) and the source, provide a link to the Creative Commons license, and indicate if changes were made. The Creative Commons Public Domain Dedication waiver (http://creativecommons.org/publicdomain/zero/1.0/) applies to the data made available in this article, unless otherwise stated. 